\title{
THE STABILITY OF BANKRUPTCY PREDICTORS IN THE CONSTRUCTION AND MANUFACTURING INDUSTRIES AT VARIOUS TIMES BEFORE BANKRUPTCY
}

\author{
Michal Karas, Mária Režňáková
}

\section{Introduction}

According to $\mathrm{Wu}$ (2010), the internal causes of firm bankruptcy may be seen in insufficient management skills, marketing and an inability to compete. They are reflected in company performance. For this reason, accounting data, or rather financial ratios, are a frequent source of information for assessing the stability and viability of an enterprise.

The literature (Chen \& Hsiao, 2008) categorizes companies undergoing business crises as follows:

- Companies lacking the capital to manage the business and starting to have problems paying their short-term debts (current liabilities) - see Deakin (1972) and Gilson (1989). Financially, this condition is detectable in the values of current liquidity, quick liquidity, accounts receivable, cash flow, total asset turnover, and other factors.

- Companies with a negative value of retained earnings for two consecutive periods or negative growth for at least 1 year. The signs of financial problems appear in the following indicators (Altman, 1983): asset profitability, sales receipts, earnings before and after taxes, and operating profit margin.

- Companies whose shares on a public stock market show an overall drop, are excluded from trading, or withdrawn from the market.

Timely recognition of signs pointing to potential bankruptcy provides a chance to avert it. This is why the economic research has long been on a quest for indicators that could signal the threat of bankruptcy at the earliest possible time. In devising a model, it is rather difficult to collect sufficient data on bankrupt companies, as bankruptcy is relatively rare in business. The first models (Altman (1968), Ohlson (1980),
Zmijewski (1984) and others) were designed on the basis of financial ratios calculated using company data one year prior to bankruptcy (the period $t+1$ ). One of the methods of increasing the accuracy of a model is to use indicators covering several years before bankruptcy (e.g. Perry et al., 1984). Deakin (1972) found that the ranking of predictor significance changes with receding time. Deakin's conclusion was confirmed by the work of Grice and Dugan (2001). Shumway (2001) criticizes the earlier bankruptcy models (of Altman, Zmijewski and Ohlson) as static since the time factor is ignored. These issue were also considered by Henerby (1996) who, aided by Cox's model (see Cox, 1972), analyzed the appropriateness of cash-flow-based indicators for predicting bankruptcy, and concluded that these indicators are statistically most significant 3 years before the event and can therefore serve as early indicators. Lin, Liang, and Chen (2011) summarize this problem in the following way: "Early studies tend to treat financial ratios measuring profitability, liquidity and solvency as significant indicators for the detection of financial difficulties. However, reliance on these financial ratios can be problematic. The order of their importance, for example, remains unclear as different studies suggest different ratios as the major indicators of potential financial problems."

Another question debated by the academic community is whether the models are transferrable, i.e. whether they can be applied in any environment other than that in which they were created. From a different point of view, authors such as Platt and Platt (1990), Grice and Dugan (2001), Delina, Pácková (2013), Niemann et al. (2008) and Wu, Gaunt and Gray (2010) have pointed out this problem and indicated that the predication accuracy of 
bankruptcy models (their ability to differentiate correctly between a company threatened by bankruptcy and a prospering company) falls markedly when they are applied to a different branch, period or economic environment than the original environment. Thomas $\mathrm{Ng}$, Wong and Zhang (2011) also concur with this view and point out the need of creating models for branches such as construction, as the existing models are inappropriate for this branch. Kaplinski (2008) claims that bankruptcy prediction models should be adjusted to the economic conditions of the given country or even branch. The possible explanation could be that the significance of bankruptcy predictors is not stable over time or these predictors are specific for a given time, place and branch. As a result, it is recommended that consideration is given to external environment factors in the creation of prediction models (see Carling et al., 2007; Gertler, 2015).

The research referenced above inspired the authors to verify the conclusions presented using data on companies operating in the Czech Republic. The purpose of this article is to verify whether bankruptcy predictors are specific in terms of industry or time. Another objective is to establish which predictors can signal an imminent bankruptcy more than one period before bankruptcy occurs.

\section{Sample and Methods}

The sample under investigation is comprised of 34,533 companies in two branches in the Czech Republic, namely Manufacturing and Construction. This number represents the total number of observations available in the AMADEUS (Analysis Major Database for European Sources) database, from which the data under investigation was obtained. As significantly fewer companies do business in construction than in manufacturing, we did not create a select group (for instance, through the stratification method), so as not to compromise the comparability of the select groups in terms of their share in the total number of companies operating in the individual industries. There are 34,229 active (or financially healthy companies) and 304 bankrupt companies (a year before bankruptcy), i.e. the share of bankrupt companies is only $0.88 \%$, which is one more reason why we did not create a select group. For more details, see the following table (Tab. 1).

The bankrupt companies in our sample declared bankruptcy during years 20082013 , although data on these companies was monitored over 5 years. In the case of the bankrupt companies, the first interval studied is the year before bankruptcy which is referred to as period $t+1$. The period studied is then the period between the years 2003 and 2013. We test a set of 16 financial ratios covering several aspects of a company's financial health. These ratios are often used in studies on bankruptcy prediction problems (see Tian et al., 2015; Gordini, 2014; Laitinen et al., 2014; Kwak et al., 2014; Bányiová et al., 2014; Faltus, 2014; Carling et al., 2007; Karas \& Režňáková, 2013; Cút, 2014). As certain authors point out the instability of bankruptcy predictors over time (e.g. Beaver, 1966; Deakin, 1972; Henerby, 1996; Niemann et al., 2008), we have used financial ratios found in the relevant publications over the last decade for our tests.

One of the frequently mentioned risk factors affecting companies, and thus relevant to bankruptcy, is company size (see for example Ohlson, 1980; Peel \& Peel, 1987; Karas \& Režňáková, 2013; Homolka, Knápková, \& Pavelková, 2015). This factor was not, however, examined in this research because the group of going concerns and bankrupt companies was heterogeneous in terms of size.

\section{Tab. 1: Numbers of Investigated Companies}

\begin{tabular}{l|r|r|r|r|r|r}
$\begin{array}{c}\text { Branch (according to NACE } \\
\text { rev 2. Main section) }\end{array}$ & \multicolumn{1}{|c|}{ Active } & \multicolumn{1}{c|}{$\%$} & \multicolumn{1}{c|}{$\begin{array}{c}\text { Bank- } \\
\text { rupt }\end{array}$} & \multicolumn{1}{c|}{$\%$} & \multicolumn{1}{c|}{ Total } & \multicolumn{1}{c}{$\%$} \\
\hline C - Manufacturing & 27,748 & $81.07 \%$ & 161 & $52.96 \%$ & 27,909 & $80.82 \%$ \\
\hline F - Construction & 6,481 & $18.93 \%$ & 143 & $47.04 \%$ & 6,624 & $19.18 \%$ \\
\hline Total & 34,229 & $100.00 \%$ & 304 & $100.00 \%$ & 34,533 & $100.00 \%$ \\
\hline
\end{tabular}

Source: own analysis of data from the Amadeus database 


\begin{tabular}{|c|c|c|c|c|c|c|c|c|c|c|c|}
\hline No. & Ratio & Abbreviation & 1 & 2 & 3 & 4 & 5 & 6 & 7 & 8 & 9 \\
\hline 1. & Current ratio & CR & $x$ & $x$ & & $\mathrm{x}$ & & $x$ & & & $\mathrm{x}$ \\
\hline 2. & Working capital/total assets & WC/TA & & & & $\mathrm{x}$ & $x$ & $x$ & & $\mathrm{x}$ & $\mathrm{x}$ \\
\hline 3. & Working capital/sales & WC/S & & & & & & & & $x$ & \\
\hline 4. & EBIT/total assets & EBIT/TA & $x$ & & $x$ & & & & & & \\
\hline 5. & EBITDA/total assets & EBITDA/TA & & & & & & & $x$ & $x$ & \\
\hline 6. & EAT/equity & ROE & & $x$ & & & & & & & \\
\hline 7. & Current liabilities/total assets & $\mathrm{CL} / \mathrm{TA}$ & & & & & & $x$ & & & \\
\hline 8. & $\begin{array}{l}\text { Long-term liabilities/total } \\
\text { assets }\end{array}$ & LTL/TA & & & & & & & & $\mathrm{x}$ & \\
\hline 9. & Debt-equity ratio & DER & & $x$ & & & & & & & \\
\hline 10. & Sales/total assets & S/TA & $x$ & & & $x$ & & $x$ & & & $\mathrm{x}$ \\
\hline 11. & Sales/stocks & S/St. & inv. & & & & & & inv. & & \\
\hline 12. & Sales/debtors & S/Deb. & inv. & & & & & inv. & & & \\
\hline 13. & EBIT/interest & EBIT/Int. & & & & & & & & $\mathrm{x}$ & \\
\hline 14. & EBITDA/interest & EBITDA/Int. & & inv. & & & & $x$ & & & \\
\hline 15. & Fixed assets/total assets & FA/TA & & & & & & & & $\mathrm{x}$ & \\
\hline 16. & Sales/operating revenue & S/OR & inv. & & & & & & & & \\
\hline
\end{tabular}

Source: Tian et al. (2015), Gordini (2014), Laitinen et al. (2014), Kwak et al. (2014), Bányiová et al. (2014), Faltus (2014), Carling et al. (2007), Karas and Režňáková (2013), Cút (2014)

Note: Inv. - the ratio was used in the mentioned literature in an inverse form. Source: 1 - Tian et al. (2015), 2 - Gordini (2014), 3 - Laitinen et al. (2014), 4 - Kwak et al. (2014), 5 - Bányiová et al. (2014), 6 - Faltus (2014), 7 - Carling et al. (2007), 8 - Karas, Režňáková (2013), 9 - Cút (2014).

Significant predictors were first identified on a univariate basis using the parametric t-test or F-test, and the multivariate non-parametric Boosted Trees method was also applied for the sake of comparison.

\subsection{T-test and F-test}

For identifying potential predictors we used a two sample t-test with equal or rather unequal variances. The test procedure can be described in the following way. To test the equality of variances, the F-test was applied.

Let there be two independent random samples $\left(X_{1}, \ldots, X_{n}\right)$ from distribution $N\left(\mu_{1:} \sigma^{2}\right)$ respectively $\left(Y_{1}, \ldots, Y_{m}\right)$ from distribution $N\left(\mu_{2} ; \sigma^{2}\right)$. We assume that $n \geq 2 ; m \geq 2 ; \sigma^{2}>0$.

The t-test tests the null hypothesis that the difference between the means of both groups $\left(\mu_{1}, \mu_{2}\right)$ is equal to some constant $(\Delta)$, in most cases to zero $(\Delta=0)$, i.e.:

$$
H_{0}: \mu_{1}-\mu_{2}=\Delta
$$

Against the alternative hypothesis

$$
H_{1}: \mu_{1}-\mu_{2} \neq \Delta
$$

The test criterion, under the assumption of equal variances, can be written in the following form:

$$
\begin{aligned}
& |T|=\mid \frac{\bar{X}-\bar{Y}-\Delta}{\sqrt{(n-1) \cdot S_{x}^{2}+(m-1) \cdot S_{y}^{2}}} . \\
& \cdot \sqrt{\frac{n m \cdot(n+m-2)}{n+m} \mid \geq t_{n+m-2(\alpha)}} \mid
\end{aligned}
$$

where $\bar{X}, \bar{Y}, S_{x}^{2}, S_{y}^{2}$ are characteristics of the two random samples.

The test criterion, under the assumption of unequal variances, can be written in the following form: 


$$
\frac{|\bar{X}-\bar{Y}|}{S} \geq \frac{v_{x} t_{n-1}(\alpha)+v_{y} t_{m-1}(\alpha)}{v_{x}+v_{y}}
$$

where

$$
\begin{aligned}
& S_{x}=\frac{1}{n-1}\left(\sum_{i=1}^{n} X_{i}^{2}-n \bar{X}^{2}\right), \\
& S_{y}=\frac{1}{n-1}\left(\sum_{i=1}^{m} Y_{i}^{2}-m \bar{Y}^{2}\right) \\
& S=\sqrt{\frac{S_{x}^{2}}{n}+\frac{S_{y}^{2}}{m}}, v_{x}=\frac{S_{x}^{2}}{n}, v_{y}=\frac{S_{y}^{2}}{m}
\end{aligned}
$$

To test the equality of variances, the traditional F-test can be applied, inter alia, in order to verify the zero hypothesis

$$
H_{0}: \sigma_{x}=\sigma_{y}
$$

based on the presumption that both samples are independent and come from a normal distribution. The testing criterion is as follows (see Meloun \& Militký, 1998, p. 196):

$$
F=\max \left(\frac{S_{x}^{2}}{S_{y}^{2}} ; \frac{S_{y}^{2}}{S_{x}^{2}}\right)
$$

if the $\mathrm{H}_{0}$ hypothesis is true and $S_{x}^{2}>S_{y}^{2}$ the test statistics have an F-distribution with $v_{1}=(n-1)$ and $v_{2}=(m-1)$ degrees of freedom.

\subsection{Boosted Trees Method}

The method of Boosted Trees is a combination of the classification and regression trees method (CART) (see Breiman et al., 1983), with a boosting algorithm introduced by J. Friedman (see Friedman, 2001). Using the boosting algorithm increases the accuracy of the classification algorithm to which it is applied by progressively reducing the error term (Braun \& Mues, 2012; Friedman, 2001). The resultant classification rule represents a set of many "weak" learners. The boosting algorithm is most often applied to CART, but an Artificial Neural Network (ANN) application may be encountered as well (Kim \& Kang, 2010).

\section{Classification and Regression Trees (CART)}

The basic idea behind the trees is the division of a complex problem of feature space in a set of smaller parts known as regions $(R)$ which can be described through simpler models (for example, constants). The central problem of the method of using trees is establishing the optimal divisional boundaries $t$ between these regions $R$. The boundaries are established in such a way that the demarcated regions, or trees, fulfill specific defined properties. This property of the regions, or trees, is defined as a node impurity and the aim of the method is its minimization. For classification purposes, where the output can take the value $1,2, \ldots$, $K$, it is possible to describe node impurity in the following way, see (Hastie et al., 2009, p. 306).

In the $m$-th node, representing the $m$-th region $R_{m}$ with $N_{m}$, the number observed is a proportion of the group $k$ in the node $m$, given by the relation:

$$
\hat{p}_{m k}=\frac{1}{N_{m}} \sum_{x_{i} \in R_{m}} I\left(y_{i}=k\right)
$$

It is then necessary to define the majority of observed elements of the $k$-th group in the node $m$ as:

$$
k(m)=\arg \max x_{k} \hat{p}_{m k}
$$

Node impurity of the tree $T$ or $Q_{m}(T)$ can be defined using several standards, for example cross-entropy or deviance

$$
-\sum_{k=1}^{K} \hat{p}_{m k} \log \hat{p}_{m k}
$$

Deviance as a level of node impurity was used here as part of the presented research.

\section{Boosting}

Boosting is a general approach for making the final deciding rules as a set of several "weak" rules or classifiers. Amongst the boosting algorithms AdaBoost.M1 is one most frequently applied, see (Freund \& Schapire, 1997), the principle of which will be described further. The basis of boosting is the gradual application of the classifier $G(X)$ to the repeatedly modified version of data and thus to gradually produce other $M$ "weak" classifiers $G_{m}(X), m=1,2, \ldots, M$.

The resulting classifier $G_{\text {final }}(X)$ is then made up of the individual partial rules $G_{m}(X)$ which are given the weights $\alpha_{m}$. The output is standardized to attain a value of only -1 or 1 , see (Hastie et al., 2009, p. 338). 
The weights $\alpha_{1}, \alpha_{2}, \ldots, \alpha_{M}$ are calculated using a boosting algorithm representing the partial contribution of each classifier $G_{m}(X)$. The modification of data in each step of the boosting algorithm is the application of the weights $w_{1}, w_{2}, \ldots, w_{N}$ for each pair of training data $\left(x_{i}, y_{i}\right)$, where $i=1,2, \ldots, N$. At the start of the algorithm the weights are set at the value $w_{i}=1 / N$. In every other iteration $m=2,3, \ldots$, $M$ the weights of individual observations are adjusted. In the $m$-th iteration the weights of those observations which had been wrongly classified in the previous step are increased by the classifier $G_{m-1}(X)$, while the weights of those which were successful are lowered. By this method, the wrongly classified observation is given more attention in order to increase the accuracy of the whole rule. The algorithm Adaboost.M1 is well described in Hastie et al. (2009, p. 338-339). A useful feature of this method is that it allows the sorting out of the variables $x_{j}$ according to their relative influence $I$ on the variability of the approximation function $\hat{G}(x)$ across the entire division of input predictors, this measurement can be described as follows, see (Friedman, 2001):

$$
I_{j}=\left(E_{x}\left[\frac{\partial \hat{G}(x)}{\partial x_{j}}\right] \cdot \operatorname{var}_{x}\left[x_{j}\right]\right)^{1 / 2}
$$

Among the advantages of the Boosted Trees method, aside from its nonparametric nature (the data need not be normally distributed), is its tolerance for outliers in the input variable space (Twala, 2010). In addition, the method can even capture non-linear relationships between the variables (Guelman, 2012). Since the lack of normality and the presence of outliers tend to be commonplace in financial data (Barnes, 1982; Schumway, 2001; Wu et al., 2010) it can be expected that a method which is immune to these aspects will deliver higher classification accuracy.

Financial ratios were defined for each analyzed company in the sample of active companies and in the sample of bankrupt companies. The ratios were calculated according to the status of the company (i.e. active or bankrupt), the last reported year $(2008,2009, \ldots, 2013)$, i.e. in case of bankrupt companies the year of bankruptcy, and finally according to the number of years prior to bankruptcy $(t+1, t+2, \ldots, t+5)$.
The F-test and t-test were applied to test the potential differences between the samples of active and bankrupt companies' ratios and the $p$-values of these tests were analyzed.

\section{Results}

First, the results of univariate testing by means of the t-test and the F-test will be presented, with results of the application of the Boosted Trees method to follow.

\subsection{Results of Univariate Testing}

The ratios were tested separately for every year prior to bankruptcy $(\mathrm{t}+1, \mathrm{t}+2, \ldots \mathrm{t}+5)$. For example, CR C1 is the current ratio calculated using the data on construction companies one year prior to bankruptcy.

The Tab. 3 below shows the results of the t-test and the F-test for the above-defined indicators for companies for 2008 through 2012, i.e. it contains results for companies that went bankrupt in 2013, plus results for financially healthy companies. The equality of the variance of values of financial indicators was assessed at the level of $5 \%$ significance of the F-test. Due to the large volume of results, indicators that were not significant even at the $10 \%$ level during this period (bankruptcy in 2013) were not included in the table. The statistical significance of the t-test results was highlighted by the use of the following designation: *statistically significant at the $10 \%$ level, ${ }^{* *}$ statistically significant at the $5 \%$ level, ${ }^{* * *}$ statistically significant at the $1 \%$ level.

Similarly, company data for 2007-2011 was analyzed, i.e. the year in which bankruptcy occurred was decisive - 2012 in this particular case, and further, for years 2006 through 2010 (bankruptcy year 2011), for years 2005 through 2009 (i.e. bankruptcy year 2010) and years 2004 through 2008 (i.e. bankruptcy year 2009). Since a description of the results for a period of five years before bankruptcy in the abovementioned manner would be excessive (960 test results), it was necessary to aggregate the results in a certain way. For this reason, we indicate moments preceding bankruptcy $(t+1, \ldots, t+5)$, when the relevant indicator was significant without specifying the relevant bankruptcy year (the "last year"). The number of periods before bankruptcy is recorded in an abbreviated manner by a figure, where " 1 " represents the period preceding bankruptcy by 1 year (i.e. the $t+1$ period), etc. The number of 


\section{Tab. 3: The t-test and F-test results for the analyzed ratios in the period 2008-2012}

\begin{tabular}{|c|c|c|c|c|c|c|c|c|}
\hline & t-stat. & df & p-val. & t-stat. ${ }^{*}$ & $d f^{*}$ & p-val. ${ }^{*}$ & F-stat. & p-val..* \\
\hline CR $2 C^{* *}$ & 2.5282 & 4263 & 0.011501 & 2.43117 & 53.215 & 0.018451 & 1.08 & 0.634200 \\
\hline CR $4 C^{* *}$ & 2.9240 & 3389 & 0.003478 & 2.16025 & 45.666 & 0.036038 & 1.86 & 0.000872 \\
\hline CR $2 M^{*}$ & -0.30490 & 2032 & 0.760475 & -0.74771 & 71.725 & 0.457078 & 7.11 & 0.000000 \\
\hline CR $4 M^{*}$ & -2.11242 & 1746 & 0.034792 & -0.93430 & 44.397 & 0.355202 & 5.86 & 0.000000 \\
\hline EBIT/Int. $1 \mathrm{C}^{* * *}$ & -0.2786 & 2203 & 0.780596 & -2.69028 & 434.532 & 0.007414 & 491.19 & 0.000000 \\
\hline EBIT/Int. $2 C^{* *}$ & -0.4548 & 2069 & 0.649333 & -2.05933 & 25.251 & 0.049915 & 24.98 & 0.000000 \\
\hline EBIT/Int. $3 C^{* * *}$ & -0.3261 & 1827 & 0.744376 & -2.87739 & 447.563 & 0.004202 & 424.59 & 0.000000 \\
\hline EBIT/Int. $4 \mathrm{C}^{*}$ & -0.4594 & 1666 & 0.646012 & -1.78321 & 37.730 & 0.082599 & 19.28 & 0.000000 \\
\hline EBIT/TA $4 M^{*}$ & 0.04754 & 3498 & 0.962086 & 0.30246 & 3492.443 & 0.762318 & 1388.00 & 0.000000 \\
\hline EBIT/TA $5 M^{*}$ & 0.12531 & 3105 & 0.900289 & 0.77600 & 3077.361 & 0.437809 & 990.53 & 0.000000 \\
\hline EBITDA/Int. $1 C^{* \star *}$ & -0.3757 & 1872 & 0.707147 & -3.72636 & 510.969 & 0.000216 & 640.29 & 0.000000 \\
\hline EBITDA/Int. $3 C^{* \star *}$ & -0.3798 & 1618 & 0.704154 & -3.21931 & 599.612 & 0.001354 & 485.79 & 0.000000 \\
\hline EBITDA/Int. $4 C^{* *}$ & -0.5304 & 1494 & 0.595927 & -2.47817 & 38.196 & 0.017739 & 30.96 & 0.000000 \\
\hline EBITD & -7.3612 & 3133 & 0.000000 & -2.10017 & 30.043 & 0.044214 & 13.93 & 0.000000 \\
\hline EBITDA & -1.9268 & 2886 & 0. & -1.7 & 28.481 & 0.087140 & 1.19 & 0.457900 \\
\hline EBITDA/TA $5 C^{* * *}$ & -0.9026 & 2336 & 0.366818 & -2.81518 & 25.485 & 0.009272 & 10.70 & 0.000000 \\
\hline FA/TA $1 M^{* * *}$ & 0.02000 & 1504 & 0.984044 & 0.15798 & 1468.815 & 0.874494 & 1877.10 & 0.000000 \\
\hline FA/TA $2 M^{* * *}$ & -0.12646 & 1420 & 0.899388 & -0.96590 & 1069.734 & 0.334311 & 695.21 & 0.000000 \\
\hline FA/TA $3 M^{* *}$ & -0.08528 & 1325 & 0.932054 & -0.65588 & 1312.237 & 0.512019 & 16734.33 & 0.000000 \\
\hline FA/TA $4 M^{* * *}$ & -0.02011 & 1226 & 0.983960 & -0.15145 & 1225.567 & 0.879647 & 4068.06 & 0.000000 \\
\hline FA/TA $5 \mathrm{M}^{* *}$ & -0.19532 & 1137 & 0.845173 & -1.48635 & 1136.478 & 0.137463 & 3126.21 & 0.000000 \\
\hline FA/TA $1 C^{* * *}$ & -2.8363 & 4962 & 0.004583 & -3.54023 & 62.376 & 0.000762 & 1.58 & 0.024866 \\
\hline FA/TA $3 C^{* *}$ & -1.8206 & 4050 & 0.068740 & -2.05191 & 53.777 & 0.045061 & 1.28 & 0.258011 \\
\hline S/Deb. $1 \mathrm{M}^{* \star *}$ & 0.24018 & 846 & 0.810247 & 2.45836 & 843.581 & 0.014157 & 30561.81 & 0.000000 \\
\hline S/Deb. $2 \mathrm{M}^{* \star *}$ & 0.18902 & 818 & 0.850127 & 2.03449 & 816.507 & 0.042225 & 31395.27 & 0.000000 \\
\hline S/Deb. $4 \mathrm{M}^{* *}$ & 0.35327 & 790 & 0.723977 & 3.40328 & 640.173 & 0.000707 & 1710.21 & 0.000000 \\
\hline $\mathrm{S} / \mathrm{OR} 1 \mathrm{M}^{* * *}$ & 0.45755 & 1163 & 0.647362 & 3.16173 & 94.965 & 0.002106 & 126.28 & 0.000000 \\
\hline S/TA $1 M^{* * *}$ & 0.47726 & 3157 & 0.633214 & 2.92033 & 3143.366 & 0.003521 & 2496.99 & 0.000000 \\
\hline $\mathrm{S} / \mathrm{TA} 2 \mathrm{M}^{* * *}$ & 2.42592 & 2826 & 0.015332 & 10.49020 & 298.188 & 0.000000 & 38.03 & 0.000000 \\
\hline S/TA $3 M^{* * *}$ & 2.40274 & 2491 & 0.016345 & 7.92118 & 153.663 & 0.000000 & 16.01 & 0.000000 \\
\hline S/TA $4 M^{* *}$ & 0.73328 & 2161 & 0.463467 & 3.94037 & 2011.465 & 0.000084 & 372.60 & 0.000000 \\
\hline S/TA $5 M^{* *}$ & 0.26586 & 2914 & 0.79 & 1.79391 & 2900.744 & 0.072931 & 4043.73 & 0.000000 \\
\hline S/TA $3 C^{* * *}$ & 26 & 4050 & 0.0 & -3.48700 & 56.827 & 0.0 & 3.43 & 0.000000 \\
\hline $\mathrm{S} / \mathrm{TA} 4 \mathrm{C}^{* * *}$ & -1.3817 & 3545 & 0.167137 & -4.32837 & 66.242 & 0.000052 & 11.39 & 0.000000 \\
\hline S/TA $5 C^{* *}$ & -1.0647 & 3050 & 0.287092 & -2.15736 & 51.207 & 0.035693 & 4.36 & 0.000000 \\
\hline
\end{tabular}




\section{Tab. 4: Summary of t-test results}

\begin{tabular}{l|c|c}
\multicolumn{1}{c|}{ Ratio/Branch } & Manufacturing & Construction \\
\hline CR & $2,3,4$ & $2,3,4$ \\
\hline WC/TA & 3 & 1,3 \\
\hline WC/S & 2 & \\
\hline EBIT/TA & $1,2,3,4$ & $1,2,3,4$ \\
\hline EBITDA/TA & & \\
\hline ROE & 3 & n.a. \\
\hline CL/TA & n.a. & 1 \\
\hline LTL/TA & $1,3,4$ & $1,3,4$ \\
\hline DER & $1,2,3,4$ & $1,2,3,4$ \\
\hline S/TA & $1,2,3,4$ & 3,4 \\
\hline S/St. & $1,2,4$ & n.a. \\
\hline S/Deb. & $1,2,3,4$ & $1,2,3,4$ \\
\hline EBIT/Int. & n.a. & $1,2,3,4$ \\
\hline EBITDA/Int. & $1,2,3,4$ & $1,2,3,4$ \\
\hline FA/TA & 1 & 1 \\
\hline S/OR & Soure & \\
\hline
\end{tabular}

Source: own analysis of data from the Amadeus database

valid observations for certain indicators was insufficient, and such results are therefore given as „n.a." in the Tab. 4.

One year before bankruptcy $(t+1)$, the significant indicators of return on assets (ROA) in the manufacturing industry are calculated as the share of earnings before interest, taxes, depreciation and amortization (EBITDA/TA). Indicators evaluating indebtedness and debt service capacity are then calculated as the debt/ equity ratio (DER 1) and interest coverage, i.e. the ratio earnings before interest and taxes and interest (EBIT/Int. 1). Other important indicators evaluate asset management ability: asset turnover, inventory turnover and receivables turnover (S/TA 1, S/St. 1 and S/Deb. 1). The last group of indicators relevant for the period $t+1$ consists of indicators showing the composition of revenues, or assets, namely, sales and operating revenue ratio (S/OR 1$)$ and the fixed assets/ total assets ratio (FA/TA 1). These indicators represent $50 \%$ of the indicators analyzed (8 out of 16). Two years before bankruptcy (period $t+2$ ), ROA indicators (EBIT/TA 2 or EBITDA/ TA 2, with EBIT/TA being significant only in this particular period) are once again significant in this industry. Then indicators evaluating liquidity and ability to pay interest, such as current ratio (CR 2) and interest coverage (EBIT/Int. 2). Other significant indicators evaluate asset management capacity (S/TA 2, S/St. 2 and S/ Deb. 2). The last group of indicators significant for this period are asset composition indicators (FA/TA 2). These indicators represent $50 \%$ of the indicators analyzed (8 out of 16). In the third year before bankruptcy (period $t+3$ ), the same significant indicators as in the previous period apply: EBITDA/TA 3, CR 3, EBIT/Int. 3, S/TA 3, S/St. 3, FA/TA 3. Another significant indicator is DER 3, the significance of which was not confirmed a year earlier. The ratio of net working capital to assets (WC/TA 3 ) turned out to be newly significant. This form of liquidity indicator is only significant in this period. The same applies to the short-term indebtedness indicator (CL/TA). These indicators represent $56 \%$ of the indicators analyzed (9 out of 16 ). In the fourth year before bankruptcy $(t+4)$, $50 \%$ of the indicators analyzed continue to be significant - specifically the EBITDA/TA 4, CR 3, DER 3, EBIT/Int. 3, S/TA 3, S/St. 3 or S/ Deb. 3, FA/TA 3 ratios. In the fifth year before bankruptcy $(t+5)$, no indicator is significant with regard to the industry. 
Now on to the construction industry. Similarly, no indicator is significant with regard to the industry in the fifth year before bankruptcy $(t+5)$. In all four periods before bankruptcy $(t+1$, $t+2, t+3, t+4)$, ROA indicators are significant in the EBITDA/TA form, as is the indicator of asset structure (FA/TA), revenue composition indicators (S/OR), interest coverage indicators evaluating company indebtedness (EBIT/Int.) and asset management indicators in the form of stock turnover (S/St). The debt-equity ratio indicator (DER 1) was only significant one year before bankruptcy $(t+1)$. Other important indicators are indicators evaluating the asset management capacity, specifically the total assets turnover for 3 periods (namely S/TA 1, S/TA 3, S/TA 4). The current ratio indicator (CR 2, CR 3, CR 4) proved to be significant in three periods, similarly to the assets turnover indicator (S/TA 1, S/TA 3, S/TA 4). The indicator of management of business credit (receivables) in the form of sales to debtors is an important predictor in the third and fourth years before bankruptcy (S/Deb. 3, S/Deb. 4). Another indicator boasting a high degree of distinction is a modified liquidity indicator calculated as the net working capital to sales ratio (WC/S 1, WC/S 3).
It needs to be pointed out in connection with this indicator that it did not turn out to be significant with regard to the manufacturing industry. The number of statistically significant predictors changed over the years. Their number was the lowest two years before bankruptcy $(t+2)$, specifically 6 ; in the other years, their number was 8 or 9 (in $\mathrm{t}+3)$.

\subsection{Results of Multivariate Testing}

The results were further verified by means of an alternative method, specifically the Boosted Trees method which makes it possible to obtain a different perspective on the significance of the indicators examined. For the purpose of application of the method, the sample was divided into a part serving for model derivation $(70 \%)$ and a part serving for model testing $(30 \%)$. In accordance with the literature (see Hastie et al., 2009, p. 363), the overall number of terminal nodes was limited to 6 . The parameter of the number of terminal nodes determines the maximum number of iterations between variables.

The model is derived by means of an iterative calculation aimed at obtaining the optimum number of trees where the total error

\section{Fig. 1: Process of iterative calculation of Boosted Trees model - sample of manufactu- ring companies}

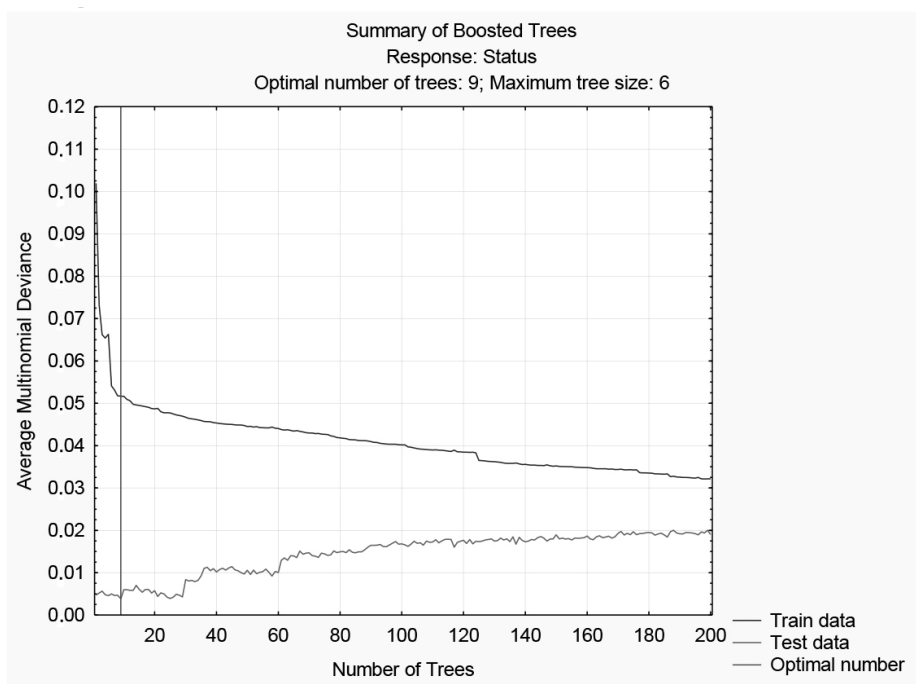

Source: own analysis of data from the Amadeus database 
Tab. 5: Summary of results of Boosted Trees method application

\begin{tabular}{l|c|c|c|c}
\multirow{2}{*}{ Sample } & \multicolumn{2}{|c|}{ Risk (Estimate) } & \multicolumn{2}{c}{ Standard (error) } \\
\cline { 2 - 5 } & Manufacturing & Construction & Manufacturing & Construction \\
\hline Train & 0.083051 & 0.056039 & 0.002840 & 0.001264 \\
\hline Test & 0.000000 & 0.020290 & 0.000000 & 0.007591 \\
\hline
\end{tabular}

Source: own analysis of data from the Amadeus database

(or deviance in this case) is minimal. The process of the calculation for manufacturing companies is shown in the graph above (Fig. 1).

According to the graph, the optimum number of trees per manufacturing industry sample is 9 , while the maximum number of trees was 200 .
The specific error obtained in the training and test sample for both industries is shown in the Tab. 5.

Average Multinomial Deviance (risk estimate) values are lower in the model for the manufacturing industry than in the model for

\begin{tabular}{|c|c|c|c|c|c|}
\hline Tab. 6: & $\begin{array}{l}\text { of appli } \\
\text { ies }\end{array}$ & on of the $B$ & rees $\mathrm{m}$ & d - sample & ufacturing \\
\hline Ratio & RI & Ratio & RI & Ratio & RI \\
\hline S/St. 1 & 1.0000 & DER 2 & 0.4561 & S/Deb. 5 & 0.3118 \\
\hline EBITDA/TA 2 & 0.8966 & CR 5 & 0.4558 & EBIT/TA 5 & 0.3118 \\
\hline WC/S 1 & 0.8406 & WC/TA 2 & 0.4431 & EBITDA/TA 5 & 0.2981 \\
\hline S/TA 1 & 0.8213 & S/St. 4 & 0.4423 & ROE 1 & 0.2931 \\
\hline DER 4 & 0.7836 & WC/TA 1 & 0.4313 & CL/TA 4 & 0.2903 \\
\hline CR 2 & 0.7310 & CL/TA 2 & 0.4028 & EBIT/Int. 5 & 0.2758 \\
\hline S/Liab. 2 & 0.7168 & WC/S 2 & 0.3943 & DER 1 & 0.2616 \\
\hline S/Liab. 1 & 0.7132 & S/Deb. 1 & 0.3823 & S/Liab. 5 & 0.2604 \\
\hline WC/S 5 & 0.7018 & S/TA 3 & 0.3790 & FA/TA 5 & 0.2377 \\
\hline CR 4 & 0.6921 & FA/TA 2 & 0.3720 & FA/TA 3 & 0.2354 \\
\hline EBIT/TA 2 & 0.6827 & S/TA 4 & 0.3689 & EBIT/TA 4 & 0.2211 \\
\hline EBITDA/TA 3 & 0.6410 & S/Deb. 2 & 0.3653 & FA/TA 4 & 0.1950 \\
\hline ROE 4 & 0.6409 & S/St. 3 & 0.3530 & DER 3 & 0.1941 \\
\hline ROE 2 & 0.6155 & CR 3 & 0.3525 & S/St. 5 & 0.1908 \\
\hline S/Deb. 3 & 0.6029 & WC/TA 3 & 0.3462 & EBITDA/TA 4 & 0.1855 \\
\hline CR 1 & 0.5777 & FA/TA 1 & 0.3434 & ROE 3 & 0.1765 \\
\hline S/Liab. 4 & 0.5671 & WC/TA 4 & 0.3421 & EBIT/Int. 1 & 0.1637 \\
\hline EBITDA/TA 1 & 0.5342 & WC/S 4 & 0.3411 & DER 5 & 0.1216 \\
\hline EBIT/TA 3 & 0.5254 & S/Liab. 3 & 0.3364 & ROE 5 & 0.1202 \\
\hline S/Deb. 4 & 0.5254 & S/St. 2 & 0.3351 & EBIT/Int. 4 & 0.1186 \\
\hline S/TA 2 & 0.5212 & CL/TA 5 & 0.3296 & EBIT/Int. 3 & 0.1044 \\
\hline EBIT/TA 1 & 0.5202 & CL/TA 3 & 0.3243 & EBIT/Int. 2 & 0.0776 \\
\hline WC/S 3 & 0.4778 & S/TA 5 & 0.3199 & & \\
\hline CL/TA 1 & 0.4707 & WC/TA 5 & 0.3136 & & \\
\hline
\end{tabular}


construction companies, and a more accurate model, or rather a greater significance of variables in the model, can thus be expected.

However, for the purposes of the research presented here, the contribution of the individual variables to the discrimination ability of the model is of key importance. This property of variables can be presented within the Boosted Trees method as the relative importance (RI) of an indicator, where number 1 is allocated to the most important indicator, and numbers at an interval $(1 ; 0)$ are allocated to the other indicators. The results for manufacturing companies are summarized in the Tab. 6.

According to the Boosted Trees method, one year before bankruptcy $(t+1)$, inventory turnover is the most significant indicator
(S/St.), with RI equal to $100 \%$. The second most important indicator is net working capital to sales (WC/S 1) with $\mathrm{RI}=84 \%$, followed by total assets turnover (S/TA 1 ) with $\mathrm{RI}=82.1 \%$. The following indicators still have an RI higher than 50\%: liabilities turnover (S/Liab. 1), CR 1 and return on assets indicators (EBITDA/TA 1, EBIT/TA 1) with RI. Two years before bankruptcy $(\mathrm{t}+2)$, return on assets (EBITDA/TA 2) with $\mathrm{RI}=89.7 \%$ is the most important indicator, followed by current ratio (CR 2) with $\mathrm{RI}=73.1 \%$ and liabilities turnover (S/Liab. 2). Other indicators with $\mathrm{RI}>50 \%$ are ROA (EBIT/TA 2), ROE (EAT/equity 2) and total assets turnover (S/TA 2). Three years before bankruptcy $(t+3)$, ROA (EBITDA/TA 3 ) is once again the most important indicator, with $\mathrm{RI}=64.1 \%$.

\begin{tabular}{|c|c|c|c|c|c|}
\hline Tab. 7: & $\begin{array}{l}\text { f appli } \\
\text { es }\end{array}$ & on of Boost & meth & sample of & tion \\
\hline Ratio & $\mathbf{R} \mathbf{I}$ & Ratio & $\mathbf{R} \mathbf{I}$ & Ratio & $\mathbf{R I}$ \\
\hline CL/TA 4 & 1.0000 & CR 2 & 0.4077 & WC/S 1 & 0.2697 \\
\hline S/TA 1 & 0.9973 & EBITDA/TA 1 & 0.4011 & EBITDA/TA 3 & 0.2652 \\
\hline WC/TA 4 & 0.9409 & EBITDA/TA 2 & 0.3966 & WC/S 4 & 0.2605 \\
\hline CL/TA 2 & 0.7709 & WC/S 5 & 0.3937 & EBITDA/Int. 1 & 0.2469 \\
\hline $\mathrm{CL} / \mathrm{TA} 1$ & 0.7446 & EBIT/TA 3 & 0.3874 & CR 5 & 0.2347 \\
\hline CL/TA 3 & 0.7234 & FA/TA 3 & 0.3817 & S/Deb. 2 & 0.2320 \\
\hline EBITDA/TA 4 & 0.7009 & CR 1 & 0.3765 & FA/TA 5 & 0.2265 \\
\hline WC/TA 2 & 0.6889 & S/Liab. 2 & 0.3728 & ROE 3 & 0.2236 \\
\hline WC/TA 3 & 0.6734 & DER 3 & 0.3669 & WC/S 2 & 0.2224 \\
\hline WC/TA 1 & 0.6424 & S/TA 5 & 0.3571 & ROE 4 & 0.2216 \\
\hline S/TA 2 & 0.5914 & CR 3 & 0.3446 & S/St. 1 & 0.2112 \\
\hline EBIT/TA 4 & 0.5502 & EBIT/TA 5 & 0.3405 & DER 5 & 0.2055 \\
\hline EBIT/TA 1 & 0.5163 & ROE 2 & 0.3401 & EBITDA/Int. 4 & 0.1999 \\
\hline S/Liab. 1 & 0.5156 & FA/TA 2 & 0.3383 & EBITDA/TA 5 & 0.1881 \\
\hline S/TA 3 & 0.4956 & FA/TA 4 & 0.3357 & EBITDA/Int. 3 & 0.1862 \\
\hline S/TA 4 & 0.4911 & S/Liab. 5 & 0.3335 & S/Deb. 3 & 0.1667 \\
\hline CL/TA 5 & 0.4778 & ROE 1 & 0.3237 & S/St. 2 & 0.1373 \\
\hline EBIT/TA 2 & 0.4593 & S/Liab. 3 & 0.3120 & ROE 5 & 0.1365 \\
\hline S/Deb. 5 & 0.4518 & CR 4 & 0.3047 & S/St. 3 & 0.1201 \\
\hline WC/TA 5 & 0.4512 & WC/S 3 & 0.2955 & S/St. 5 & 0.1104 \\
\hline FA/TA 1 & 0.4448 & S/Liab. 4 & 0.2864 & S/St. 4 & 0.1032 \\
\hline DER 2 & 0.4214 & DER 4 & 0.2850 & EBITDA/Int. 5 & 0.1026 \\
\hline S/Deb. 1 & 0.4187 & EBITDA/Int. 2 & 0.2757 & & \\
\hline DER 1 & 0.4136 & S/Deb. 4 & 0.2725 & & \\
\hline
\end{tabular}


Receivables turnover (S/Deb. 3) and another variant of ROA (EBIT/TA 3) are still above the threshold of $\mathrm{RI}>50 \%$. In the fourth year before bankruptcy $(t+4)$, indebtedness (DER 4$)$ is the most important indicator with a high relative importance $(78.4 \%)$. The current ratio (CR 4$)$ is also high $(69.2 \%)$. Indicators with $\mathrm{RI}>50 \%$ also include ROE (EAT/equity 4), liabilities turnover (S/Liab. 4) and receivables turnover (S/Deb. 4).

Results for construction companies are displayed in the Tab. 7.

According to the Boosted Trees method, a year before bankruptcy, asset turnover (S/TA 1) with RI $=99.7 \%$ is the most important indicator in the construction industry, followed by short-term indebtedness (CL/TA 1) with $\mathrm{RI}=74.46 \%$ and the indicator of relative size of the net working capital (WC/TA 1) with $\mathrm{RI}=64.24 \%$ and $\mathrm{ROA}$ (EBIT/TA 1). All these indicators show that the difference between successful companies and companies threatened by bankruptcy lies in the degree to which they utilize their assets. The last of the indicators with $\mathrm{RI}>50 \%$ is the receivables turnover indicator (S/Liab. 1). Two years before bankruptcy $(t+2)$, the following are the most important indicators (indicated in descending order): CL/TA 2 (RI = 77.09\%), WC/TA 2 $(\mathrm{RI}=68.89 \%)$ and S/TA 2. For the remaining indicators, $\mathrm{RI}<50 \%$. It is interesting that the same indicators are important predictors even three years before bankruptcy, i.e. in $t+3$. The relative importance for all three indicators is lower than in $t+2$. The most important predictor four years before bankruptcy $(t+4)$ is the indicator of short-term indebtedness (CL/TA 4), to which the highest relative importance value of all the indicators analyzed was allocated. The high value of relative importance $(94.09 \%)$ of the indicator of net working capital relative size (WC/TA 4) was highly surprising. An equally surprising finding was that the ROA indicator was the most important predictor in the fourth year before bankruptcy (EBITDA/TA 4) with $\mathrm{RI}=70.1 \%$, or EBIT/TA $4(\mathrm{RI}=55 \%)$. The relative importance of the remaining indicators is under $50 \%$. Overall, the number of indicators identified as important predictors using the relative importance indicator is lower in the construction industry than the manufacturing industry. However, the Boosted Trees method does not make it possible to compare the importance of indicators between sets, or between industries in this particular case, and this finding cannot, therefore, be deemed to be of key importance. However, it can be assumed that further, as yet untested, indicators that would reflect the specific features of the industry better will need to be sought for the construction industry.

\section{Discussion}

The accuracy of bankruptcy prediction models is determined by the effectiveness of their predictors. Studies such as Platt and Platt (1990), Grice and Dugan (2001), Niemann et al. (2008) and Wu, Gaunt, and Gray (2010) have pointed out that the predication accuracy of bankruptcy models often falls markedly when they are applied to a different branch, period or economic environment than that from which the data on which they were developed was taken. In this article, we have tested the differentiation ability of financial ratios in two different ways: on a univariate basis, using a parametric t-test or F-test, and using a non-parametric Boosted Trees method which permits multivariate testing. This method was used as an auxiliary method so that we could identify the relationship between variables as accurately as possible. However, the results are linked to the use of the method, and the results obtained by different methods cannot be combined. Despite this, the information obtained is extremely interesting.

A comparison of the importance of predictors based on the results of univariate testing clearly shows differences between the two industries examined. Industry-specific indicators can be identified in this way:

- Return on total assets, calculated using earnings before interest and taxes, which is specific to the manufacturing industry in $\mathrm{t}+2$ (EBIT/TA2). The importance of this indicator is confirmed by other studies which examine the importance of bankruptcy predictors by alternative methods. Schumway (2001) may be mentioned, although he only assessed the importance of indicators in the manufacturing industry.

- Our results show that the relative size of net working capital to total assets (WC/TA) is specific for the manufacturing industry. This indicator is often encountered in bankruptcy models (Wu, Gaunt, \& Gray, 2010; Lin Liang \& Chen, 2011; Kwak et al., 2014; Bányiová et al., 2014; Faltus, 2014), though our research confirmed its importance in only one industry and period (specifically, $t+3$ ). 
- The indicator of relative size of net working capital to sales (WC/S) as one of the liquidity indicators. This indicator is specific for the construction industry.

Both WC/TA and WC/S indicators are solvency indicators. This category includes the current ratio $(\mathrm{CR})$ indicator. The importance of these indicators relates in particular to the average values of indicators of stock and short term receivables (in our investigation, expressed as a share in total assets, i.e. St/TA, $\mathrm{CL} / \mathrm{TA})$. The average (median) values of St/TA are lower in construction than in manufacturing. Similarly, there are marked differences between average and median values of CL/TA in both sectors; the CL/TA indicator is substantially higher in construction. Construction is therefore financed from short-term resources to a greater degree than manufacturing. As a result, WC/ TA is significantly lower in construction than in manufacturing. This indicator turned out to be negative in all the periods under investigation. If we compare the development of $\mathrm{WC} / \mathrm{S}$ between industries, differences in the values of these indicators are again seen: the average and median values of this indicator are lower in the construction industry in every year. When the development of the two indicators over time is analyzed, the decline in the value of this indicator in the construction industry is much steeper. A marked change in the values of the WC/S indicator occurs three years before bankruptcy. However, this is not the case in the manufacturing industry: even bankrupt companies in the manufacturing industry have a relatively high ratio of working capital to sales (WC/S); they exhibit the highest average values two years before bankruptcy. This may be due to the nature of the industry: in the manufacturing industry, even companies threatened by bankruptcy may still own an inventory of material they have not yet sold, or their own production they may be having problems selling. Therefore, with sales declining, the values of this indicator tend to be relatively high and comparable to those of active companies. The situation in the construction industry is different: building companies purchase their inventories in relation to a specific contract. When they have no orders, and therefore no sales, they do not purchase inventories. This is why there is a marked difference between the values of this indicator in companies going bankrupt and prospering companies.
Although ROE is considered one of the most important indicators of the return on capital invested, it turned out to be rather insignificant with regard to bankruptcy prediction; i.e. there are more important bankruptcy indicators. This may be related to the fact that bankruptcy results from the company's inability to pay liabilities, and more pronounced changes of indicators in the bankrupt companies group occur in other indicators. Moreover, growth of indebtedness results in a ROE increase (financial leverage effect), until the rate becomes too high in terms of creditor risk. ROE correlates with ROA indicators which are not affected by the degree of the company's indebtedness and reflect the company's ability to obtain a better return on the capital invested. The ROA indicator was tested in two forms: EBIT/TA and EBITDA/TA. In terms of prediction of bankruptcy, i.e. the company's inability to pay its liabilities, EBITDA/TA turned out to be more significant. This is logical because EBITDA corresponds to the value of the operating CF indicator, i.e. expresses the company's ability to generate income from operating activities. EBITDA also turned out to be important in measuring interest coverage (EBITDA/Int), i.e. an indicator assessing the company's creditworthiness, in the construction industry.

According to results obtained by the Boosted Trees method, the ratio short-term debt to total assets is the most important predictor for the construction industry (CL/TA 4), i.e. in the fourth year before bankruptcy. The information value of this indicator for bankruptcy prediction in the construction was confirmed across the whole horizons (see Tab. 7). In the manufacturing industry, this indicator ranks only 24th, and as such can be considered specific to the construction industry. Another indicator typical for the industry appears to be the indicator of relative size of net working capital, i.e. WC/TA (see Tab. 7). The value of the net working capital indicator is calculated on the basis of the value of inventory, receivables and shortterm liabilities as indicators of the efficiency of management of operating activities. It indicates that the difference between financially healthy and failing companies in the construction industry is affected in particular by the efficiency of management of operating activities. This conclusion is confirmed by the relative importance of the sales turnover indicator a year before bankruptcy (S/TA 1) which is the second 
most important indicator for the construction industry according to the Boosted Trees method. As we are dealing with the relative importance of these indicators, it should be mentioned that the value of the WC/TA indicator is largely influenced by the value of current liabilities which may be the reason for the great importance of this indicator in the construction industry. The last important indicator in the construction industry is the ROA indicator in the form of EBITDA/TA. This suggests that EBITDA can be an extremely important indicator for companies, and can be viewed as an indicator that also provides information on operating cash flow in a company.

Other important indicators turned out to be turnover indicators frequently found in bankruptcy prediction models. In the manufacturing industry, the inventory turnover indicator (S/St. 1) turned out to be the most important predictor in the set of indicators under examination. It can therefore be deduced that bankruptcy problems in the manufacturing industry are cumulated in the inventory management area. A further two turnover indicators (S/Liab, S/Deb.) may be replaced with the indicator of relative size of net working capital to sales (WC/S) which exhibits high relative importance values one and five years before bankruptcy (see Tab. 6). This indicator may also replace the current ratio indicator. In terms of return, ROA is given preference over $\mathrm{ROE}$, in the form of EBITDA/TA, which means that important differences between financially healthy companies and companies threatened with bankruptcy lie in particular in the ability to generate operating cash flow. The importance of this indicator was confirmed in our previous research using an alternative method (see Karas \& Režňáková, 2013). It is a remarkable finding that only one indicator measuring company indebtedness can be viewed as an important bankruptcy predictor in the fourth year before bankruptcy (DER 4).

However, the results obtained by the Boosted Trees method cannot be used to compare the importance of the variables tested between industries. Only their importance within the industry can be assessed. This is due to the fact that maximum importance (i.e. 1) is allocated to the most important factor in the set tested; the importance of the other variables is relative to this value, and is only valid in the industry analyzed. When the importance of variables within a particular industry is assessed, complex relations between variables are taken into account and these cannot be captured by single-dimensional tests.

Bankruptcy model studies are often implicitly based on Beaver's original presumption (see Beaver, 1966) that with impending bankruptcy, the difference between healthy (active) and failing companies deepens. For this reason, indicators defined for $t+1$ are used most frequently to generate bankruptcy models. The authors probably rely on the presumption that at that moment the identifiable difference between active companies and companies threatened with bankruptcy will be most prominent. However, the question is whether problems in economic management can be identified earlier, i.e. in $t+2$ through $t+5$ before bankruptcy in our case. Another question to be discussed is whether the importance of predictors of the same type changes over time or is stable, i.e. if the same type of indicators can be used to predict bankruptcy over a period of several years. An alternative presumption is that the importance of indicators changes, i.e. an indicator that is an important predictor a year before bankruptcy does not have to be an important predictor five years before bankruptcy.

It can be inferred from the results of univariate testing (see Tab. 4) that financial ratios are unstable over time. For instance, the current ratio indicator $(\mathrm{CR})$ is an important predictor in both industries in $t+2$ through $t+4$, but not an important predictor in $t+1$. Other examples of indicators that are unstable over time in the manufacturing industry are short-term indebtedness indicators (CL/TA) or indicators of net working capital to assets (WC/TA) which are important in $t+3$, but not in $\mathrm{t}+2$ or $\mathrm{t}+1$.

The examination of moments preceding bankruptcy $(t+1, t+2, \ldots, t+5)$, when the individual indicators are significant, made it possible to identify time-specific indicators or indicators that are important at a specific time before bankruptcy. This property was manifested in the manufacturing industry with regard to return on assets indicators in $t+2$ (EBIT/TA 2), the relative size of net working capital to total assets in $t+3$ (WC/TA 3 ), shortterm indebtedness in $\mathrm{t}+3$ (CL/TA 3), and with regard to the sales structure indicator in $t+1$ (S/OR 1). In the construction industry, only one 
time-specific indicator was identified: the debt to equity ratio in $t+1$ (DER 1 ).

On the other hand, indicators of return on assets (EBITDA/TA), important in $t+1, t+2, t+3$ and $t+4$, can be viewed as stable over time in both industries under examination. Indicators of inventory turnover (S/St.) and asset composition (FA/TA), which are also important in $t+1, t+2, t+3$ and $t+4$, can also be deemed to be stable over time in both industries. The remaining time-stable indicators are significant in only one of the relevant industries. In the manufacturing industry, this property is also found in the interest coverage at the level of earnings before tax and interest paid (EBIT/Int.) or the indicator of total assets turnover (S/TA); both are important in $t+1, t+2, t+3$ and $t+4$. In the construction industry, this property is also found in the interest coverage at the level of earnings before tax, interest paid and amortization (EBITDA/Int.) and in the sales structure indicator ( $\mathrm{S} / \mathrm{OR}$ ); both are important in $\mathrm{t}+1, \mathrm{t}+2$, $t+3$ a $t+4)$. When evaluating the results using the multivariate method, it was established that even when the indicators are stable over time between the individual periods preceding bankruptcy $(t+1, \ldots, t+5)$, they are manifested with a varying degree of importance. In other words, an indicator that is most important in $\mathrm{t}+1$ is not necessarily most important in another period, i.e. $t+2$ through $t+5$. EBITDA/TA in the manufacturing can serve to illustrate this: in $\mathrm{t}+2$ it is the most important indicator, while in $t+4$ it is the second least important indicator.

The most important indicators for the creation of bankruptcy prediction models depending on the business sector can be recommended on the basis of the results of univariate testing (see Tab. 4). The table provides all indicators that were important for the prediction of bankruptcy in at least one of the sets tested (an example of results of the testing of one of the sets is provided in Tab. 3). Their importance, or frequency of occurrence, varies. If we were to select indicators that are important in multiple sets tested, the selection of indicators could be narrowed down significantly. Statistical significance of the following indicators was found to exist in at least three of the sets tested (at the $1 \%$ or $5 \%$ level of significance) with regard to companies in the manufacturing industry: EBITDA/TA 2, S/TA 1 , S/TA 3, S/St. 3, FA/TA 1, FA/TA 2, S/OR. If the same criterion is applied to the construction industry, two indicators can be recommended for the construction of bankruptcy prediction models in the construction industry: S/St. 1 and FA/TA 3. As the number of important predictors in the construction industry is lower than in the manufacturing industry according to the Boosted Trees method, we have applied less stringent requirements to the selection of variables for the construction of bankruptcy models. If we look at indicators that are important predictors in at least two of the sets tested, the following indicators can also be recommended: EBITDA/TA 2, EBITDA/TA 4, S/TA 5, S/St. 4, EBITDA/Int. 1, EBITDA/Int. 3, EBITDA/Int. 4, FA/TA 1, S/OR 1 and S/OR 3.

\section{Conclusions}

According to Perry et al. (1984) one of the methods of increasing the accuracy of a bankruptcy prediction model is to use indicators covering several years before bankruptcy. In this research we analyze the significance of bankruptcy predictors in the context of the branch and time prior bankruptcy. The research was conducted using data from 2004 through 2013 concerning companies that went bankrupt in 2008 through 2013. The research focused on financial ratios concerning companies in the manufacturing and construction industries. Data for the total of 34,229 active companies and 304 companies that went bankrupt during the aforesaid period was analyzed. The research confirmed our presumption that bankruptcy predictors are both industry and time specific. Certain indicators were naturally found to be important bankruptcy predictors in both industries, but at the same time certain indicators were identified as industry-specific (i.e. they did not occur in the other industry under examination). Such indicators are frequently associated with a specific period of time preceding the bankruptcy, i.e. are not important in all five time periods under examination. For manufacturing companies, such specific indicators are the return on assets indicators calculated using earnings before interest and taxes (EBIT/TA 2, i.e. in the second year before bankruptcy), the net working capital to total assets indicator (WC/TA 3, i.e. in the third year before bankruptcy), and the indicator of short-term indebtedness (CL/TA 3, i.e. in the third year before bankruptcy). In the construction industry, such specific indicators are the net working capital to sales indicator 
(WC/S 1, WC/S 3) and the interest coverage indicator (EBITDA/Int. for all four years before bankruptcy, i.e. $t+1$ through $t+4$ ). If all these indicators were to be included in a model for an alternative industry, they would probably reduce its accuracy.

On the other hand, certain indicators were identified whose inclusion in the model would probably increase its prediction capacity. These are indicators that can be used to distinguish failing and active companies with a greater time interval, i.e. several years before bankruptcy. Four years before bankruptcy $(t+1$ through $t+4$ ), the indicators return on assets (EBITDA/ $\mathrm{TA}$ ), inventory turnover (S/St.) and asset composition (FA/TA) are important predictors in both the manufacturing and the construction industries.

Previous research has focused in particular on the construction of bankruptcy models for manufacturing companies. For our research, we have used precise predictors from published research which was probably the reason for the higher number of relatively important predictors identified by means of the Boosted Trees method in the manufacturing industry as compared to the construction industry. However, this method does not make it possible to compare the importance of indicators between sets, or between industries in this particular case. However, it can be concluded that it will be necessary to search for new, as yet untested, indicators for the construction industry which will better reflect the specific features of this industry.

This paper is the output of the specific research project 'Selected Questions of Financial Management of Companies in the International Environment' of the Internal Grant Agency of Brno University of Technology, with Registration Number FP-S-15-2877.

The students, Zuzana Baranovičová, Pavla Fajtová, Jana Hrůzová, Zuzana Szováková and Karel Štoll, i.e. students of the master's study program "Accounting and Financial Management" participated in the research.

\section{References}

Altman, E. I. (1968). Financial Ratios, Discriminant Analysis and the Prediction of Corporate Bankruptcy. The Journal of Finance, 23(4), 589-609. doi:10.1111/j.1540-6261.1968. tb00843.x.
Altman, E. I. (1983). Corporate Financial Distress: A Complete Guide to Predicting, Avoiding and Dealing with Bankruptcy. New York: John Wiley and Sons.

Bányiová, T., Bieliková, T., \& Piterková, A. (2014). Prediction of Agricultural Enterprises Distress Using Data Envelopment Analysis. In O. Deev, V. Kajurová, \& J. Krajíček (Eds.), Proceedings of the 11th International Scientific Conference European Financial Systems 2014 (pp. 18-25). Brno: Masaryk University.

Barnes, P. (1982). Methodological implications of non-normally distributed financial ratios. Journal of Business Finance and Accounting, 9(1), 51-62. doi:10.1111/j.1468-5957.1982.tb00972.x.

Beaver, W. H. (1966). Financial Ratios as predictors of Failure. Journal of Accounting Research. Empirical Research in Accounting: Selected Studies, 4(1), 71-111. doi:10.2307/2490171.

Braun, I., \& Mues, C. (2012). An experimental comparison of classification algorithms for imbalanced credit scoring data sets. Expert Systems with Applications, 39(3), 3446-3453. doi:10.1016/j.eswa.2011.09.033.

Breiman, L., Friedman, J. H., Olshen, R., \& Stone, C. (1983). Classification and Regression Trees. Monterey, CA: Wadsworth \& Brooks/ Cole Advanced Books \& Software.

Carling, K., Jacobson, T., Lindé, J., \& Rozsbach, K. (2007). Corporate credit risk modelling and the macroeconomy. Journal of Banking \& Finance, 31(3), 845-868. doi:10.1016/j.jbankfin.2006.06.012.

Cox, D. R. (1972). Regression Models and Life-Tables. Journal of the Royal Statistical Society. Series B (Methodological), 34(2), 187-220. doi:10.2307/2985181.

Cút, S. (2014). Prediction of Company Financial Distress Using Neural Network Based on the Radial Basis Function. In Y. Zhang (Ed.), Lecture Notes in Management Science (pp. 4551). Singapore: Singapore Management and Sports Science Institute.

Deakin, E. B. (1972). A Discriminant Analysis of Predictors of Business Failure. Journal of Accounting Research, 10(1), 167-179, doi:10.2307/2490225.

Delina, R., \& Pácková, M. (2013). Validácia predikčných bankrotových modelov v podmienkach SR. E\&M Ekonomie a Management, 16(3), 101-112.

Faltus, S. (2014). Prediction of Agricultural Enterprises Distress Using Data Envelopment 
Analysis. In O. Deev, V. Kajurová, \& J. Krajíček (Eds.), Proceedings of the 11th International Scientific Conference European Financial Systems 2014 (pp. 173-177). Brno: Masaryk University.

Freund, Y., \& Schapire, R. (1997). A decision-theoretic generalization of online learning and an application to boosting. Journal of Computer and System Sciences, 55(1), 119-139. doi:10.1006/jcss.1997.1504.

Friedman, J. H. (2001). Greedy Function Approximation: A Gradient Boosting Machine. Annals of Statistics, 29(5), 1189-1232. doi:10.1214/aos/1013203451.

Gertler, L'. (2015). Interactions of Unconventional Monetary Policy Measures with the Euro Area Yield Curve. Czech Journal of Economics and Finance, 65(2), 106-126.

Gordini, N. (2014). A genetic algorithm approach for SMEs bankruptcy prediction: Empirical evidence from Italy. Expert Systems with Applications, 41(14), 6433-6445. doi:10.1016/j.eswa.2014.04.026.

Gilson, S. C. (1989). Management turnover and financial distress. Journal of Financial Economics, 25(2), 241-262. doi:10.1016/0304405X(89)90083-4.

Grice, J. S., \& Dugan, M. T. (2001). The limitations of bankruptcy prediction models: Some cautions for the researchers. Review of Quantitative Finance and Accounting, 17(2), 151-166. doi:10.1023/A:1017973604789.

Guelman, L. (2012). Gradientboosting trees for auto insurance loss cost modelling and prediction. Expert Systems with Applications, 39(3), 3659-3667. doi:10.1016/j.eswa.2011.09.058.

Hastie, T., Tibshirani, R., \& Friedman, J. (2009). The Elements of Statistical Learning: Data Mining, Inference, and Prediction. New York: Springer-Verlag.

Henerby, K. L. (1996). Do Cash Flows Variables Improve the Prediction Accuracy of a Cox Proportional Hazards Model for Bank Failure? The Quarterly Review of Economics and Finance, 36(3), 395-409. doi:10.1016/S1062-9769(96)90023-X.

Homolka, L., Knápková, A., \& Pavelková, D. (2015). Plastics Cluster Members and Their competitors - DEA benchmarking study. In E. Pastuszková, Z. Crhová, J. Vychytilová, B. Vytrhlíková, \& A. Knápková (Eds.), Proceedings of the 7th International Scientific Conference Finance and Performance of Firms in Science, Education and Practice (pp. 409-415). Zlín: Tomas Bata University in Zlín.
Chen, L. H., \& Hsiao, H. D. (2008). Feature selection to diagnose a business crisis by using a real GA-based support vector machine: An empirical study. Expert Systems with Applications, 35(3). doi:10.1016/j. eswa.2007.08.010.

Karas, M., \& Režňáková, M. (2013). Bankruptcy Prediction Model of Industrial Enterprises in the Czech Republic. International Journal of Mathematical Models and Methods in Applied Sciences, 7(5), 519-531.

Kapliński, O. (2008). Usefulness and credibility of scoring methods in construction industry. Journal of civil engineering and management, 14(1), 21-28. doi:10.3846/1392-3730.2008.14.21-28.

Kim, M. J., \& Kang, D. K. (2010). Ensemble with neural networks for bankruptcy prediction. Expert Systems with Applications, 37(4), 3373-3379. doi:10.1016/j.eswa.2007.05.019.

Kwak, W., Cheng, Y., Ni, J., Shi, Y., Gong, G., \& Yan, N. (2014). Bankruptcy Prediction for Chinese Firms: Comparing Data Mining Tools with Logit Analysis. Journal of Modern Accounting and Auditing, 10(10), 1548-6583.

Laitinen, E. K., Lukason, O., \& Suvas, A. (2014). Behaviour of Financial Ratios in Firm Failure Process: An International Comparison. International Journal of Finance and Accounting, 3(2), 122-131. doi:10.5923/j.ijfa.20140302.09.

Lin, F., Liang, D., \& Chen, E. (2011). Financial ratio selection for business crisis prediction. Expert Systems with Applications, 38(12), 15094-15102. doi:10.1016/j.eswa.2011.05.035.

Meloun, M., \& Militký, J. (1994). Statistické zpracováni experimentálních dat. Praha: Plus.

Niemann, M., Schmidt, J. H., \& Neukirchen, M. (2008). Improving performance of corporate rating prediction models by reducing financial ratio heterogeneity. Journal of Banking \& Finance, 32(3), 434-446. doi:10.1016/j. jbankfin.2007.05.015.

Ng, S. T., Wong, J. M. W., \& Zhang, J. (2011). Applying Z-score model to distinguish insolvent construction companies in China. Habitat International, 35(1), 599-607. doi:10.1016/j. habitatint.2011.03.008.

Ohlson, J. A. (1980). Financial Ratios and the Probabilistic Prediction of Bankruptcy. Journal of Accounting Research, 18(1), 109-131. doi:10.2307/2490395.

Perry, L., Henderson, G., \& Cronan, T. (1984). Multivariate analysis of corporate bond ratings and industry classification. 


\section{Ekonomika a management}

Journal of Financial Research, 7(1), 27-36. doi:10.1111/j.1475-6803.1984.tb00351.x.

Platt, D. H., \& Platt, M. B. (1990). Development of a Class of Stable Predictive Variables: The Case of Bankruptcy Prediction. Journal of Business Finance \& Accounting, 17(1), 31-51. doi:10.1111/j.1468-5957.1990. tb00548.x.

Peel, M. J., \& Peel, D. A. (1987). Some further empirical evidence on predicting private company failure. Accounting and Business Research, 18(69), 57-66. doi:10.1080/0001478 8.1987.9729348.

Shumway, T. (2001). Forecasting Bankruptcy More Accurately: A Simple Hazard Model. Journal of Business, 74(1), 101-124. doi:10.2139/ssrn.171436.

Tian, S., Yu, Y., \& Guo, H. (2015). Variable selection and corporate bankruptcy forecasts. Journal of Banking \& Finance, 52(1), 90-100. doi:10.1016/j.jbankfin.2014.12.003.

Twala, B. (2010). Multiple classifier application to credit risk assessment. Expert Systems with Applications, 37(4), 3326-3336. doi:10.1016/j.eswa.2009.10.018.

$\mathrm{Wu}, \quad W . \quad$ (2010). Beyond business failure prediction. Expert Systems with
Applications, 37(3), 2371-2376. doi:10.1016/j. eswa.2009.07.056.

Wu, Y., Gaunt, C., \& Gray, S. (2010). A comparison of alternative bankruptcy prediction models. Journal of Contemporary Accounting \& Economics, 6(1), 34-45. doi:10.1016/j.jcae.2010.04.002.

Zmijewski, M. E. (1984). Methodological issues related to the estimation of financial distress prediction models. Journal of Accounting Research, 22(1), 59-82. doi:10.2307/2490859.

Ing. Michal Karas, Ph.D.

Brno University of Technology Faculty of Business and Management Institute of Finances karas@fbm.vutb.cz

prof. Ing. Mária Režňáková, CSc. Brno University of Technology Faculty of Business and Management Institute of Finances reznakova@fbm.vutbr.cz 


\section{THE STABILITY OF BANKRUPTCY PREDICTORS IN THE CONSTRUCTION AND MANUFACTURING INDUSTRIES AT VARIOUS TIMES BEFORE BANKRUPTCY}

\section{Michal Karas, Mária Režňáková}

This article focuses on the design of bankruptcy models, specifically the selection of suitable predictors. Previous research has drawn mainly on data concerning manufacturing companies one year before bankruptcy. Our research examines financial ratios that are suitable bankruptcy indicators in two different industries (the construction and manufacturing industries) over a period of five years prior to bankruptcy. Our main objective is to verify whether bankruptcy predictors are industry-specific. Another objective was to determine which indicators can detect signs of bankruptcy earlier than one period before bankruptcy. We presume that the application of industryspecific indicators can help increase the predictive accuracy of bankruptcy models when applied to a particular industry. Per analogiam, we assume that the inclusion of indicators capable of detecting signs of bankruptcy more than a year before its occurrence will increase their predictive capacity. Significant predictors were first identified on a linear basis using the parametric $t$-test or F-test; for the sake of comparison, a non-linear non-parametric Boosted Trees method was also applied. Data for a total of 34,229 active companies and 304 companies that went bankrupt during the relevant period was analyzed. The research confirmed our presumption that bankruptcy predictors are both industry and time specific. Four years before bankruptcy, the indicators return on assets, inventory turnover and asset structure are important predictors in both the manufacturing and construction industries. The net working capital to total assets ratio is a specific predictor for manufacturing companies in the third year before bankruptcy, as is the short-term indebtedness indicator. In the construction industry, specific predictors are the net working capital to sales ratio in the third and first years before bankruptcy, and the interest coverage indicator in all four years preceding bankruptcy. Were these indicators to be included in a model for an alternative industry, they would be likely to reduce its accuracy.

Key Words: Financial ratios, bankruptcy prediction models, time-specific predictors, branchspecific predictors, manufacturing, construction, boosted trees.

JEL Classification: G33, C51.

DOI: $10.15240 / t u l / 001 / 2017-2-009$ 